\title{
OS IMPACTOS DA MACROMUDANÇA DA SAÚDE SUPLEMENTAR: UM ESTUDO DE CASO DA CAMED
}

\section{IMPACTS OF MACRO CHANGES OF SUPPLEMENTARY HEALTH: A CASE STUDY OF CAMED}

\author{
Osvaldo Viana Filho \\ Camed - BA \\ $\underline{\text { vf1303@uol.com.br }}$
}

Jader Cristino de Souza Silva Universidade do Estado da Bahia - BA falecom@jadersouza.com.br

Roberto Brazileiro Paixão

Escola de Administração da Universidade Federal da Bahia - UFBA robertobrazileiro@gmail.com

Submissão: $20 / 10 / 2014$

Aprovação: 15/10/2015 


\title{
RESUMO
}

Este artigo buscou identificar como as macromudanças no setor da saúde suplementar no Brasil impactaram na dinâmica organizacional da Caixa de Assistência dos Funcionários do Banco do Nordeste do Brasil (Camed), ou seja, articular o fenômeno da regulação da saúde suplementar e o construto de mudança organizacional. A abordagem da pesquisa foi qualiquantitativa, com a utilização da técnica do Discurso do Sujeito Coletivo (DSC). Foram realizadas entrevistas semiestruturadas com gestores da organização, totalizando quatorze respondentes. Os achados desta pesquisa buscam trazer avanços de natureza teórica e metodológica para os construtos ligados à mudança organizacional e à saúde suplementar. Conclui-se que, na dimensão intencionalidade, a mudança na Camed foi de natureza reativa e voluntária; na dimensão objeto, as mudanças foram: estratégicas, estruturais, tecnológicas e de pessoal; na dimensão implementação, a Camed mudou de forma reeducativa/participativa.

Palavras-Chaves: Macromudanças, Mudança Organizacional, Saúde Suplementar.

\begin{abstract}
This paper aims to identify how macro changes in the sector of supplementary health in Brazil impacted the organizational dynamics of Cash Assistance for Employees of Northeast Brazilian Bank (Camed). In other words, articulate the phenomenon regulation of the supplementary health and the concept of organizational change. The research approach was qualiquantitative. The data analysis technique was the Discourse of Collective Subject, based on the Theory of Social Representations. The findings of this research bring theoretical and methodological advances to the constructs of organizational change and supplementary health. This research concludes that, in the intentionality dimension, the change in Camed was reactive and voluntary; in the object dimension, the changes were strategic, structural, technological and personnel; in the implementation dimension, Camed changed in the educational and participatory way.
\end{abstract}

Keywords: Macro Changes, Organizational Changes, Suplementary Health. 


\section{INTRODUÇÃO}

A saúde suplementar no Brasil ultrapassou o marco de quinze anos de regulação, uma vez que a Lei 9.656/98 (BRASIL, 1998) promoveu significativos ajustes ao implantar as bases da relação entre o público e o privado. O início do processo se deu com a Constituição Federal, que proporcionou liberdade à iniciativa privada para explorar a assistência à saúde, além participar de forma complementar ao Sistema Único de Saúde, o SUS (BRASIL, 1988). Como forma de compreender as características da saúde suplementar anteriores à regulação do setor, é importante destacar que existia, no Brasil, uma forte demanda social gerada em virtude de problemas quanto à prestação de serviços oriundos da assistência privada e da falta de estruturação desse setor. Tais insatisfações eram provenientes da ausência de regras para a entrada de operadoras de planos de saúde no mercado, do baixo nível de informação do consumidor, da inexistência de padrões mínimos de cobertura assistencial, da desigualdade de forças entre consumidores e operadoras de planos de saúde e das reclamações sobre a mercantilização da saúde, que, dentre outros, serviram como fatores indutores de todo o processo regulatório (RIBEIRO, 2001).

A partir desse cenário, pode-se compreender que as demandas pela regulação da saúde suplementar no Brasil emergiram de um clamor social decorrente da insegurança jurídica e, de modo mais amplo, da falta de controle sobre o setor da saúde privada. Nesse aspecto, situações como: quebra de contratos pelos planos de saúde, alterações na rede credenciada contratada sem aviso prévio e, bem assim, negativas de atendimento eram problemas comuns.

Ressalta-se, ainda, que inexistiam critérios de informação que permitissem aos consumidores diferenciar, em termos qualitativos, as operadoras de planos de saúde e os produtos ofertados. Dentro dessa tônica, as intervenções do judiciário tornaram-se constantes e contribuíram para colocar a regulação da saúde suplementar como tema prioritário na agenda do Ministério da Saúde e do Governo Federal. Com base no exposto, observa-se que as bases para a regulação do setor eram objeto de ampla discussão, que culminou com o início do marco regulatório da saúde suplementar no Brasil, no ano de 1998, a partir da Lei 9.656/98 (RIBEIRO, 2001).

Cabe assinalar, neste cenário de mudanças, que as operadoras na modalidade de autogestão em saúde passaram a cumprir as mesmas exigências impostas às demais operadoras que obtém receitas e oxigenam suas carteiras de beneficiários com a comercialização de planos. Conforme as características da autogestão, suas receitas são 
oriundas de fontes específicas formadas pela contribuição dos empregados e da empresa à qual a operadora de autogestão está vinculada, denominada, geralmente, de patrocinadora.

Por conseguinte, partindo de um cenário de macro mudanças na saúde suplementar geradas após a promulgação da Lei 9.656/98, torna-se necessário aprofundar os estudos sobre esse importante setor da economia que, conforme dados do seu órgão regulador, a Agência Nacional de Saúde Suplementar (ANS), até dezembro de 2012, era responsável por atender a 47,9 milhões de brasileiros (ANS, 2013a). Na busca de contribuir com a ampliação do conhecimento sobre o tema, este artigo tem como objetivo identificar como as macro mudanças da saúde suplementar impactaram na dinâmica organizacional da Caixa de Assistência dos Funcionários do Banco do Nordeste do Brasil S.A.(Camed), originalmente, uma operadora de planos de saúde na modalidade autogestão.

A Camed foi criada para cuidar da saúde dos funcionários e dependentes do Banco do Nordeste do Brasil S.A. (BNB), seu patrocinador, uma empresa de economia mista com mais de $90 \%$ do seu capital sob o controle do Governo Federal. Foi fundada em 1979, sendo reconhecida como uma entidade de assistência social, sem fins lucrativos, e sua sede está instalada na cidade de Fortaleza, mas sua área de atuação abrange todos os Estados da Região Nordeste e, também, Rio de Janeiro, São Paulo, Minas Gerais, Espírito Santo e Brasília (CAMED, 2013).

Neste sentido, esta investigação justifica-se pela busca da ampliação do conhecimento sobre um tema ainda recente que é o processo de regulação da saúde suplementar no Brasil, bem como no aprofundamento de um fenômeno singular, que foi a mudança organizacional que culminou na transformação de uma operadora de autogestão em saúde, numa operadora também de medicina de grupo.

Para cumprir o objetivo desta investigação, este artigo está dividido em cinco partes, incluindo esta introdução que representa a primeira delas. Na segunda parte, é apresentada a revisão de literatura sobre os dois temas basilares desta investigação: o processo regulatório da saúde suplementar e a mudança organizacional. Na terceira parte, cuidou-se de apresentar os procedimentos metodológicos realizados. A quarta parte trata dos resultados da pesquisa obtidos a partir dos discursos coletados. Na quinta e última parte são tecidas as considerações finais. 


\section{REFERENCIAL TEÓRICO}

\subsection{O processo regulatório da Saúde Complementar}

Apesar de se tratar de um setor robusto, atendendo, aproximadamente, um quarto da população do país e transacionar com recursos da ordem de $\mathrm{R} \$ 95$ bilhões de reais, inexistia antes da regulação, por parte dos organismos governamentais de controle, um efetivo acompanhamento desse importante setor da economia, permitindo às organizações que nele atuavam, a criação das suas próprias regras (ANS, 2013a).

Também, como parte desse cenário, existia, no Brasil, uma conjuminância de operadoras nas mais variadas modalidades e tipos de produtos. De 1977 a 1997/98, as empresas de medicina de grupo mais que triplicaram, e as cooperativas médicas mais que quintuplicaram em quantidade, e, de 1994/95 a 1997/98, o número de seguradoras foi duplicado (BAHIA, 2001).

Tomando por base o crescimento do número de organizações atuando na saúde suplementar, se, por um lado, esses dados evidenciam um mercado em franca expansão; por outro, constatou-se, antes do processo regulatório, um recrudescimento das mazelas do setor, acentuando problemas, decorrentes da ausência de condições mínimas para operar no mercado. Assim, a intervenção do Governo Federal na regulação do setor foi fruto da pressão política gerada pela assimetria na relação dos agentes econômicos entre si e com os consumidores, notadamente quando se levava em consideração que, no âmbito dos planos individuais, o consumidor não tinha como exercer qualquer pressão sobre melhoria de preços ou serviços, e os empregadores, apesar de possuírem, de um modo geral, o suporte da sua estrutura empresarial, não detinham domínio nem experiência em negociar com operadoras (RIBEIRO, 2001; PEREIRA, 2010).

Em termos práticos, a regulação começou a se moldar em 1997, culminando com promulgação da Lei 9.656/98, em junho de 1998, e sua consequente implementação após a criação da Agência Nacional de Saúde Suplementar (ANS), em abril de 2000 (MONTONE, 2001). A ANS tem como atribuições a regulação, a normatização, o controle e a fiscalização das atividades das operadoras de planos de saúde, englobando: a) a estrutura e operação do setor; b) a gestão econômica e assistencial via acompanhamento do controle de qualidade na prestação dos serviços; c) a formação de um banco de informações econômico-financeiras das 
operadoras, do controle dos preços, bem como a liquidação das operadoras em situação irregular (CIEFAS, 2000; RIBEIRO, 2001; UNIDAS, 2003; SANTOS, F., 2006).

Nesse contexto, a regulação em saúde no Brasil compreendeu toda a supervisão e controle do setor privado, onde, por intermédio do poder de polícia, criaram-se regras e normas de funcionamento e operação para as organizações do setor (ARAÚJO, 2004).

Em síntese, a regulação foi, na prática, a capacidade de intervir de modo indutório, normatizador, regulador ou restritivo no processo de prestação de serviços privados do modo mais abrangente possível e que se caracterizou como uma resposta às demandas sociais contra as práticas nocivas do livre mercado (SANTOS, F., 2006; PÓ, 2010).

Uma contribuição do marco regulatório foi a classificação das operadoras de plano de saúde quanto à modalidade. Isso promoveu uma relevante colaboração para o aprofundamento das discussões sobre estas organizações que, apesar de atuarem num mesmo setor, possuem características distintas. Neste sentido, as operadoras de planos de saúde foram classificadas quanto à modalidade em: a) administradora de planos; b) administradora de benefícios; c) cooperativa médica; d) cooperativa odontológica; e) filantropia; f) medicina de grupo; g) odontologia de grupo; h) seguradora especializada em saúde; i) autogestão (SANTOS, F., 2006).

As administradoras de planos e de benefícios atuam, respectivamente, na gestão e intermediação de contratos coletivos, não possuem rede credenciada e nem assumem o risco da operação. As cooperativas médicas e odontológicas atuam conforme a Lei 5.764/71, e ambas comercializam seus respectivos planos. A filantropia é uma modalidade que comercializa e opera planos de saúde, porém sem fins lucrativos e com título de entidade filantrópica obtida junto ao Conselho Nacional de Assistência Social (CNAS). A medicina e a odontologia de grupo representam o grupo das empresas com fins lucrativos e que comercializam e operam planos de saúde e odontológicos. A seguradora especializada em saúde possui fins lucrativos, bem como a característica da obrigatoriedade do reembolso de despesas médico-hospitalares. Por fim, a autogestão em saúde se caracteriza como a gestão de uma coletividade por ela mesma. Trata-se de uma modalidade que se diferencia das demais por fazer a gestão do plano de saúde dos empregados ou associados e seus dependentes, porém sem comercializá-los ou possuir finalidade lucrativa (ANS, 2011). Neste contexto, o patrocinador é o grande promotor da autogestão por meio da criação dos serviços próprios de saúde, atuando na definição das regras de contribuição e participando efetivamente por intermédio da sua contribuição pecuniária. Todavia, na maioria das autogestões, a 
manutenção do plano é realizada pela contribuição do patrocinador e dos beneficiários (coparticipação), seja por meio de um percentual fixo do salário, seja por intermédio da participação sobre os gastos com o plano (SANTOS, M., 2006).

Ademais, a regulação do setor promoveu alterações na relação entre as operadoras de planos de saúde e seu mercado, mormente por desencadear mudanças em pontos importantes da relação existente com os clientes, pois enfatizaram a correção e ajuste de questões consideradas críticas, como: a) proibição de vedação do ingresso no plano de saúde em razão de idade ou doença preexistente; b) limitação dos prazos de carências; c) assistência ao recém-nascido nos primeiros 30 dias de vida; d) exigência de um plano de referência como padrão mínimo de cobertura; e) fim da rescisão unilateral dos contratos de planos individuais; f) controle dos reajustes e definição de regras para cancelamentos por inadimplemento; g) criação de um rol de procedimentos (cobertura mínima obrigatória de procedimentos e eventos em saúde); h) padronização das faixas etárias que determinam valores de aquisição em função da idade; i) critérios para ressarcimento pelo uso do Sistema Único de Saúde (SUS) quando da utilização deste por usuário de um plano de saúde (RIBEIRO, 2001; SANTOS, F.,2006.)

Em outras palavras, a regulação foi necessária, pois inseriu mecanismos de controle financeiro e de performance econômica de mercado, como: registro das operadoras e dos produtos comercializados, comprovação de solvência e composição de reservas técnicas, controle dos preços dos planos individuais, dentre outros (SANTOS, F.,2006).

Todas essas alterações na regulação da saúde suplementar geraram macro mudanças criando um ambiente de transformação, demandando a necessidade de rápida adequação das estratégias para todas as modalidades de operadoras de planos de saúde, como forma de se adaptarem às mudanças impostas (OCKÉ-REIS et al, 2006). No caso específico desta investigação, as operadoras na modalidade de autogestão em saúde passaram a cumprir as mesmas exigências impostas às demais operadoras que obtém receitas e oxigenam suas carteiras de beneficiários com a comercialização de planos. Diante disto, as operadoras de autogestão foram compelidas à busca de alternativas para adequação às mudanças, como forma de manter a sustentabilidade.

Assim, com ênfase nas mudanças organizacionais promovidas pela Camed como forma desta adaptação, busca-se ampliar os conhecimentos acerca do impacto das mudanças no ambiente organizacional. É importante compreender como as mudanças ambientais promovem alterações estratégicas nas organizações. Assim, entende-se a trajetória de uma 
organização estudando a mudança organizacional (FARIA; FISCHER, 2001), uma vez que esta é um forte estímulo para a revisão das estratégias, procedimentos e rotinas, decorrentes da necessidade de adaptação ambiental (MACHADO-DA-SILVA; FERNANDES, 1998).

\subsection{Mudança Organizacional: formas de classificação e dimensões}

As formas de classificação e as dimensões da mudança organizacional adotadas por Wood Jr., Curado e Campos (1994); Wood Jr., (2000) e Santos (2004) permitem uma visão sistêmica do processo de mudança por integrar seus diversos elementos, segmentando-os em três aspectos: a) intencionalidade, que ilustra a relação da organização com o ambiente; b) objeto da mudança, que aborda a natureza da mudança; c) forma de implementação da mudança, que trata de explicar como ocorreu a mudança.

A classificação da mudança quanto à sua relação com o ambiente, está inserida na dimensão intencionalidade da mudança e se propõe a identificar as razões que desencadeiam o processo de mudança organizacional, respondendo a questão: por que a organização muda? Para responder a esta questão, são estudados dois segmentos da mudança, a mudança reativa e a voluntária. Segundo Santos (2004), na perspectiva reativa, a organização busca transformarse para se adequar às mudanças que ocorreram no ambiente e afetaram sua sobrevivência. Já na voluntária, a organização pretende, por meio de prospecção de cenários, planejamento estratégico, dentre outros, antecipar-se às mudanças como forma de elevar suas chances de operar uma transformação bem sucedida.

Diante desta perspectiva, seja numa abordagem reativa ou voluntária, as organizações vivenciam constantemente estados de alerta, monitoramento ambiental, planejamento e consequentes mudanças, como forma de se contrapor às ameaças geradas pelas mudanças ambientais (CASTRO; POLO; PORTO, 2008; MACHADO-DA-SILVA; GRAEFF, 2008; PINTO E COUTO-DE-SOUZA, 2009;).

Compreende-se, então, que o ambiente é elemento basilar no contexto da mudança organizacional. Para Pereira, M. (2000), as organizações são dependentes do ambiente, uma vez que não possuem controle sobre as condições necessárias à sua sobrevivência, isto as impulsiona a uma constante adequação ambiental.

A classificação da mudança quanto a sua natureza está inserida na dimensão objeto da mudança e compõe o estudo do sistema que integra o processo de mudança organizacional por meio das interações entre quatro segmentos: estratégia, estrutura, tecnologia e pessoas, e 
pretende elucidar a questão: o que muda na organização? (WOOD Jr., CURADO e CAMPOS, 1994; WOOD Jr., 2000; SANTOS, 2004).

As mudanças estratégicas são mais amplas e afetam o todo da organização e sua relação com o ambiente, definindo questões ligadas à forma de atuação, dos objetivos estratégicos, norteados por sua missão e visão. As mudanças estruturais estão ligadas às partes de uma organização. Dessa forma, centram-se nas relações de subordinação, na estrutura em geral, na operação, nos métodos de produção. As tecnológicas cuidam dos níveis de automação das fábricas, equipamentos necessários à nova dinâmica organizacional, softwares mais adequados a determinados processos e rotinas, etc. Já as mudanças relacionadas às pessoas envolvem a preocupação em alicerçar um ambiente voltado à promoção da inovação e das mudanças, à aprendizagem organizacional, às formas de reconhecimento e às políticas de seleção e formação de profissionais. Também ligadas às pessoas, as mudanças culturais representam os valores da organização e refletem-se nas formas de liderança, crenças, valores e atitudes (WOOD Jr., CURADO e CAMPOS, 1994; WOOD Jr., 2000; SANTOS, 2004).

Por fim, quando o objeto do estudo é a forma de implementação da mudança, há dois segmentos de análise: a implementação impositiva/coercitiva e a reeducativa/participativa que se propõem a responder a seguinte questão: como muda a organização? Na forma coercitiva, a organização busca a mudança por meio de ações impositivas e, normalmente, permeadas por decisões de cima para baixo, enquanto na forma reeducativa, o processo de mudança se processa de forma participativa e visa a integração das pessoas que compõem a organização às novas estratégias, dentro de um modelo voltado à transparência, capacitação e convencimento (SANTOS, 2004). Isto posto, as organizações que atuam de forma reeducativa, buscam, por meio do envolvimento das pessoas, a criação de um ambiente voltado a facilitar a aceitação das mudanças organizacionais, além de promover a criação de uma cultura que privilegie a mudança e a inovação (WOOD Jr., CURADO e CAMPOS, 1994; WOOD Jr., 2000; SANTOS, 2004). Por outro lado, as organizações que atuam dentro de uma visão coercitiva buscam, por meio de mecanismos impositivos e gestão top down, impor o processo de mudança por meio de deliberações da alta administração, sem levar em conta, normalmente, o processo de discussão, aceitação e a preparação das pessoas como agentes de mudança (OLIVA, 2002; PROTIL, 2003).

A opção por entender a mudança a partir das dimensões intencionalidade, objeto e formas de implementação representa um recorte do vasto campo que compõe o construto mudança organizacional, e tem como objetivo formar um amálgama sobre as diversas 
abordagens deste conceito. Nesse sentido, corroboram para a compreensão do multifacetado fenômeno da mudança organizacional, e colabora para conhecer o processo de transformação em que se envolvem as organizações e, especificamente nesta pesquisa, as operadoras de planos de saúde no Brasil, em especial a Camed, em função das profundas alterações do seu ambiente de negócios, devido ao processo de regulamentação do setor da saúde suplementar.

\section{PROCEDIMENTOS METODOLÓGICOS}

A presente pesquisa é de cunho qualiquantitativo. Identificou-se no Discurso do Sujeito Coletivo (DSC) uma possibilidade de abordar qualiquantitativamente o fenômeno investigado. Para Lefevre e Lefevre (2005), na técnica do DSC, o qualitativo e o quantitativo se fundem, visto que, é preciso coletivizar os resultados pela quantidade. Dessa forma, ao capturar o caráter coletivo do pensamento social, o pesquisador necessita identificar quantitativamente quantos indivíduos concorreram para a construção de um determinado DSC.

Referente às técnicas de coleta de dados, Souza-Silva (2007) ressalta que, para ser mais efetiva, a pesquisa pode incorporar um conjunto de repertórios além das entrevistas semiestruturadas. Assim, cabe ao pesquisador ampliar seu horizonte com outros artefatos e ações como a observação de campo, pesquisa de documentos internos e externos à organização e esclarecimentos posteriores às entrevistas. Em face do exposto, este trabalho utilizou este conjunto de repertórios.

A escolha metodológica recaiu sobre o estudo de caso único (YIN, 2001), de cunho eminentemente exploratório, que se justifica em função da Camed ser uma operadora de autogestão que, diante das macro mudanças do seu ambiente de negócios, promoveu a abertura para o mercado, transformando-se também numa operadora de medicina de grupo (comercializa planos), sendo o único caso do tipo, considerando seu porte e diversidade de Estados onde atua.

Desta forma, como ressalta Yin (2001), o estudo de caso é aplicável uma vez que o foco da pesquisa se encontra em fenômeno contemporâneo e específico. Também salienta Merriam (1988, apud CRUZ et al, 2010) que o estudo de caso, em função da delimitação do fenômeno, possibilita ao pesquisador mais profundidade e acuracidade na análise e descrição.

Ainda segundo Yin (2001), a qualidade do projeto de pesquisa envolve alguns testes lógicos. A utilização de múltiplas fontes de evidências, como documentos e observação de 
campo e, mais enfaticamente, as entrevistas, busca a validade de constructo, uma vez que há o encadeamento e uma composição de evidências. Um segundo teste seria a busca pela validade interna, notadamente pela tentativa de estabelecimento de uma relação de causa-efeito, que não se justifica neste trabalho pelo fato do mesmo ser exploratório. Um terceiro ponto seria a validade externa, associada a generalizações dos achados da pesquisa. Como a Camed é uma unidade com características específicas no cenário nacional, entende-se que tal generalização não é factível. E, um último ponto é a confiabilidade, que pode ser aplicável a partir do protocolo de pesquisa detalhado, o qual compõe os procedimentos metodológicos descritos nesta seção.

O emprego metodológico do DSC mostra-se, há mais de dez anos, como uma proposta que atende às demandas geradas por um estudo qualiquantitativo, uma vez que melhor atende ao desafio da obtenção de respostas, da forma mais natural possível, que permite preservar ao máximo as características individuais dos discursos dos gestores da organização. O DSC permite que depoimentos individuais com semelhanças nas suas ideias centrais possam ser somados, por possuírem conteúdos discursivos também semelhantes, fazendo com que o pensamento coletivo seja uma entidade empírica autônoma, expressa na primeira pessoa e composta por n sujeitos, configurando-se então como um "sujeito coletivo de discurso" (LEFEVRE; LEFEVRE, 2005).

A partir do exposto, compreende-se que o DSC possibilita ao pesquisador o resgate da fala do depoente. Assim, Lefevre e Lefevre (2005) consideram que, para se produzir um DSC, são necessários quatro operadores: a) as expressões-chave (trechos do depoimento que melhor retratam seu conteúdo); b) as ideias centrais (agrupamento dos sentidos dos depoimentos e dos conjuntos de depoimentos); c) as ancoragens (marcas explícitas de ideologias, valores e crenças pertinentes a alguns discursos); d) e os DSCs propriamente ditos (reunião das expressões-chave contidas nos depoimentos agrupados por ideias centrais similares).

Em termos operacionais, cada discurso individual foi analisado e teve suas expressõeschave selecionadas. Um discurso individual pode conter uma ou mais expressões-chave. $\mathrm{Na}$ sequência, tais expressões-chave foram associadas a apenas uma ideia central, sintetizadora do argumento central do discurso individual. Formou-se, então, um conjunto de ideias centrais, que continham várias expressões-chave.

De modo complementar, evidencia-se que podem ocorrer numa mesma resposta dois ou mais discursos oriundos de um mesmo sujeito, em virtude de poder ser encontradas expressões-chave de mais de uma ideia principal. De qualquer modo, tais expressões-chave 
semelhantes são a base do discurso síntese, e este é o DSC, que permite compreender a representação social de um tema ou objeto investigado, a partir da soma dos discursos coletados, como resultado da associação de ideias e valores ligados a um determinado fenômeno (CRESTANA, 2003; FALCÃO, SANTOS; LUIZ, 2008).

A efetividade do estudo em profundidade de um determinado fenômeno, numa pesquisa qualitativa, está diretamente ligada à escolha correta da unidade de análise empírica. Nesse sentido, esta pesquisa se propõe a identificar como as macro mudanças da saúde suplementar impactaram na dinâmica organizacional da Camed, sendo a mesma a unidade de análise empírica desta pesquisa, previamente caracterizada.

Convém ressaltar que a Camed foi fundada em 1979, inicialmente, com objetivo de prestar atendimento médico-hospitalar aos funcionários do BNB e seus dependentes. Posteriormente, em 1999, o Grupo Camed passou a operar no segmento de medicina de grupo por meio da organização Camed Vida e, atualmente, o Grupo é composto por quatro organizações: a Camed Saúde (autogestão); a Camed Vida (medicina de grupo); a Camed Corretora de Seguros e a Creche Paulo VI (CAMED, 2013). Sem embargo, destaca-se que a Camed Vida é classificada na ANS como operadora de grande porte, contando com 112.028 clientes, sendo que somadas, as operações de autogestão e de medicina de grupo possuem mais de 151 mil clientes (ANS, 2013b).

Utilizou-se como ferramentas de coleta do material empírico, a busca de dados via documentos internos e externos à organização, a observação e interação e as entrevistas semiestruturadas. É importante destacar que, para obtenção desses dados, em especial as entrevistas, foi solicitada a autorização da organização pesquisada, mediante a carta de solicitação de pesquisa, bem como formalizou-se com os entrevistados um termo de consentimento de pesquisa.

As entrevistas semiestruturadas foram realizadas com o corpo de gestores da organização, entre dezembro de 2012 e março de 2013. A amostra foi composta dos seguintes entrevistados (quatorze no total): a) Superintendente administrativo; b) Superintendente de controle; c) Gerente da assessoria estratégica; d) Superintendente financeiro; e) Superintendente de relacionamento com clientes e prestadores; f) Gerente de desenvolvimento organizacional; g) Gerente de desenvolvimento humano; h) Superintendente jurídico e de regulação; i) Gerente do projeto sinistralidade; j) Gerente de produtos e controladoria; l) Superintendente de tecnologia da informação; m) Diretora administrativa e financeira; n) 
Diretor de promoção à saúde; o) Gerente de marketing. As questões presentes nas entrevistas são apresentadas no Quadro 2.

\begin{tabular}{|c|c|c|}
\hline Dimensão & Categorias & Questões de investigação correlacionadas \\
\hline $\begin{array}{l}\text { Intencionalidade } \\
\text { (Por que muda?) }\end{array}$ & $\begin{array}{l}\text { - Reativas } \\
\text { - Voluntárias }\end{array}$ & $\begin{array}{l}\text { - Qual sua opinião sobre o processo de regulação da saúde } \\
\text { suplementar no Brasil? } \\
\text { - Quais os impactos para as operadoras de planos de saúde? } \\
\text { - Na sua percepção, existiram mudanças na saúde suplementar nos } \\
\text { últimos anos? Se sim, quais foram as principais mudanças? } \\
\text { - Por que estas mudanças ocorreram? }\end{array}$ \\
\hline $\begin{array}{c}\text { Objeto } \\
\text { (O que muda?) }\end{array}$ & $\begin{array}{l}\text { - Estratégicas } \\
\text { - Estruturais } \\
\text { - Tecnológicas } \\
\text { - De pessoas }\end{array}$ & $\begin{array}{l}\text { - Você acredita que as macromudanças da saúde suplementar } \\
\text { influenciaram a mudança interna na Camed? } \\
\text { - A seu ver, qual foi a principal mudança na estratégia da organização? } \\
\text { - O que estas mudanças internas trouxeram de benefícios? E de } \\
\text { malefícios? }\end{array}$ \\
\hline $\begin{array}{l}\text { Implementação } \\
\text { (Como muda?) }\end{array}$ & $\begin{array}{l}\text { - Reeducativa } \\
\text { - Coercitiva }\end{array}$ & $\begin{array}{l}\text { - Se pudéssemos voltar no tempo e você tivesse autonomia para } \\
\text { conduzir as mudanças internas, faria algo diferente? Se sim, a } \\
\text { diferença seria nas mudanças propriamente ditas, na forma de } \\
\text { implementação das mudanças ou em ambos os casos? Comente sua } \\
\text { resposta. }\end{array}$ \\
\hline
\end{tabular}

Quadro 2 - Quadro analítico da mudança organizacional.

Todas as questões ligadas à pesquisa foram repetidas igualmente aos quatorze gestores da organização que, por questões de agenda e disponibilidade, representaram $58 \%$ dos gestores da matriz e que são diretamente ligados à operação de medicina de grupo, sendo que todas as superintendências da organização pesquisada foram representadas na amostra. A maior parte dos entrevistados é do gênero feminino (57\%). Em relação ao tempo na organização, aproximadamente $65 \%$ tem menos de 6 anos e $35 \%$ tem mais de 13 anos na organização.

\section{ANÁLISE DOS RESULTADOS}

A apresentação dos resultados realizada, a seguir, utilizou os agrupamentos das ideias centrais e dos DSCs após análise das respostas dos depoentes, de acordo com as entrevistas semiestruturadas que foram gravadas e transcritas, obedecendo os procedimentos metodológicos já descritos. A partir deste ponto, a pesquisa, com base no material empírico coletado e, de acordo com o quadro analítico, avaliou a mudança organizacional por meio das suas classificações, características e dimensões. 


\subsection{Dimensão de Análise I: Intencionalidade da Mudança}

Considerando a primeira dimensão de análise desta pesquisa, que avalia a intencionalidade da mudança, foram encontradas três ideias centrais relacionadas de acordo com a tabela abaixo:

Tabela 1: Frequência por Ideia Central

Dimensão I: Intencionalidade da Mudança: Por que mudou a organização?

\begin{tabular}{|c|l|c|c|}
\hline IC & \multicolumn{1}{|c|}{ Ideia Central } & Fi & $\begin{array}{c}\text { Fi\% } \\
\text { Acum. }\end{array}$ \\
\hline IC-1 & A regulação foi necessária e promoveu mudanças na saúde suplementar. & 14 & $35 \%$ \\
\hline IC-2 & $\begin{array}{l}\text { As macromudanças da saúde suplementar, oriundas da regulação, } \\
\text { promoveram mudanças na Camed. }\end{array}$ & 14 & $70 \%$ \\
\hline IC-3 & A necessidade de novas receitas demandou mudanças na Camed. & 12 & $100 \%$ \\
\hline \multicolumn{2}{|c|}{ Total } & 40 & ----- \\
\hline
\end{tabular}

O quadro 3 apresenta o discurso do sujeito coletivo da ideia central 1 (IC-1). A partir deste discurso, pode-se observar que, apesar dos impactos internos, os gestores da Camed entendem que o modelo da saúde suplementar praticado no Brasil, antes da regulação precisava ser revisto. Esse discurso salienta que antes da regulação havia questões que necessitavam ser solucionadas, tais como: falta de segurança jurídica, controle dos reajustes nos planos individuais e padrões mínimos de cobertura. Este pensamento foi corroborado por autores como Araújo (2004); Santos, F. (2006), ao citarem que o problema da assimetria de informação existente entre compradores e fornecedores de serviço não permitia ao consumidor a devida clareza para a decisão de compra.

Em síntese, verifica-se, no discurso do sujeito coletivo em análise, a necessidade das organizações do setor se adaptarem ao novo ambiente regulado (e aí também se inclui a Camed). Dessa forma, a mudança constatada ocorreu de forma reativa.

A regulação é necessária, interessante e foi positiva para todas as partes envolvidas. Trouxe muitos benefícios para os usuários dos planos de saúde e, em grande parte, veio para moralizar a questão do direito do consumidor. Ela veio de forma recente e rápida, buscando atender uma lacuna que existe há bastante tempo. Suas resoluções têm provocado nas operadoras uma mudança organizacional muito grande. Eu acho que é um processo importante, trouxe profissionalização para as operadoras de planos de saúde, mas que não estavam prontas para essa regulação. Os planos de saúde têm que investir muito para cumprir estas exigências. As exigências têm um lado positivo porque retiraram do mercado a concorrência predatória, mas têm um lado negativo que impõe um ônus muito alto para as operadoras. Das muitas mudanças, a principal foi para dar mais transparência para o consumidor. Isso fez surgir a saúde suplementar tão regulada como hoje, que foi a necessidade de deixar claro para o consumidor o que ele está comprando.

Quadro 3 - DSC-IC-1: A regulação foi necessária e promoveu macro mudanças na saúde suplementar

De modo complementar, o quadro 4 que se refere ao discurso do sujeito coletivo da ideia central 2 (IC-2) ressalta que o processo de implantação da regulação e a sua rapidez 
promoveram macro mudanças que alteraram todo modus operandi da Camed, cristalizando-se um novo cenário de mudanças compulsórias para a referida empresa.

Dito de outra forma, a análise desse DSC permite perceber a forma reativa com que Camed teve rapidamente de se adaptar ao novo ambiente regulado por conta dos riscos de punições impostas pelo agente regulador, a ANS. Vale frisar que, no modo reativo, a organização busca adaptar-se às mudanças como forma de garantir sua sobrevivência, o que é corroborado por autores como Machado-da-Silva e Fernandes (1998) ao afirmarem que a necessidade adaptativa é um forte estímulo para a revisão das estratégias organizacionais.

A regulação impactou de forma expressiva, modificando todo o modus operandi da Camed. A regulação pegou a gente de surpresa e tivemos que nos acostumar demais com as novidades, com o que ela vai trazendo de obrigação para a gente cumprir. Vamos, aos poucos, descobrindo estes processos e temos que nos adaptar, buscando formas de atender a legislação. A operadora tem que se adaptar em curto espaço de tempo. Os impactos estão no dia a dia, as autorizações, as negativas, o aumento dos processos judiciais, é algo muito dinâmico. O impacto é muito grande porque tudo que você deixa de cumprir é multado, penalizado de forma pecuniária e administrativamente. A regulação traz uma disciplina na prestação de contas e exigências que precisam ser perseguidas e fazem com que a sustentabilidade não seja mais um desejo e sim uma obrigação.

Quadro 4 - DSC-IC-2: As macro mudanças da saúde suplementar, oriundas da regulação, promoveram mudanças na Camed.

De modo contrário ao apresentado na IC-2, onde os gestores da Camed abordaram a forma reativa de mudança promovida pela operadora visando adaptar-se à regulação do setor, no discurso do sujeito coletivo da IC-3 (quadro 5), os gestores da Camed abordam outros aspectos de caráter predominantemente econômico, que também desencadearam mudanças, sendo, desta vez, de forma voluntária. A Camed promoveu sua abertura para o mercado como forma de ampliar suas receitas, ao vislumbrar que o novo cenário macroeconômico e social do país, delineava-se como ameaçador (perda de receitas, em função da estabilização econômica, ocorrida após o Plano Real, redução de contratações, via concurso público, da sua patrocinadora, dentre outros fatores).

Em outras palavras, a mudança voluntária se processou quando a Camed iniciou o processo de transformação antes mesmo da regulação, buscando novas fontes de receitas, culminando na abertura para o mercado (medicina de grupo). Deste modo, como visto no referencial teórico, na perspectiva voluntária, a organização pretende, por meio de prospecção de cenários, planejamento estratégico, dentre outros, antecipar-se às mudanças como forma de elevar suas chances de operar uma transformação bem sucedida (SANTOS, 2004; CASTRO; POLO; PORTO, 2008). 
No passado, a Camed não conseguia crescer. Houve um achatamento das receitas por conta dos salários dos funcionários dos bancos (congelamento). Como trabalhamos com um percentual em cima da folha de pagamento, isto foi um reflexo imediato nas receitas do plano. Outro ponto é que vivemos um período com poucos concursos e na autogestão não temos um fluxo suficiente de ingressos, com o aumento da tecnologia e do envelhecimento da população, enfrentamos um novo modelo de saúde suplementar. A nossa carteira estava ficando estagnada, envelhecida. A saída foi recorrer ao mercado. Essa oxigenação foi um fator essencial para angariar novas receitas. O patrocinador não encaminhava recursos para a Camed. Houve uma limitação de recursos por parte dos órgãos reguladores do Banco. A autogestão é uma população fechada, com poucas adesões. Como poderíamos conseguir receitas, que não fossem as que viessem do Patrocinador? Tivemos que mudar!

Quadro 5 - DSC-IC-3: A necessidade de novas receitas demandou mudanças na Camed

A partir dos DSC referentes às ideias centrais 1, 2 e 3 (IC-1, IC-2 e IC-3), permite-se compreender que, na dimensão intencionalidade da mudança, o processo ocorreu na Camed de forma híbrida, sendo reativa no âmbito do atendimento às exigências geradas pelo processo regulatório e; por outro lado, sendo voluntária, sobretudo por conta da decisão estratégica de abertura para o mercado, motivada pela leitura do cenário macroeconômico e social existente à época.

\subsection{Dimensão de Análise II: Objeto da Mudança}

Em relação à segunda dimensão de análise, relacionado ao objeto da mudança, obtevese quatro ideais centrais nos discursos dos respondentes de acordo com a Tabela 2.

Tabela 2: Frequência por Ideia Central

Dimensão de Análise II: Objeto da Mudança: O que mudou na organização?

\begin{tabular}{|c|l|c|c|}
\hline IC & \multicolumn{1}{|c|}{ Ideia Central } & Fi & $\begin{array}{c}\text { Fi\% } \\
\text { Acum. }\end{array}$ \\
\hline IC-5 & $\begin{array}{l}\text { A inclusão da operação de medicina de grupo e a regulação promoveram } \\
\text { mudanças estruturais na Camed. }\end{array}$ & 14 & $29 \%$ \\
\hline IC-6 & $\begin{array}{l}\text { A Camed promoveu mudanças tecnológicas para atender às exigências da } \\
\text { ANS e da operação de medicina de grupo. }\end{array}$ & 13 & $56 \%$ \\
\hline IC-7 & $\begin{array}{l}\text { As demandas geradas em função das mudanças promovidas na Camed } \\
\text { contribuíram para uma maior profissionalização das pessoas. }\end{array}$ & 11 & $79 \%$ \\
\hline IC-8 & A principal mudança estratégica da Camed foi a abertura para o mercado. & 10 & $100 \%$ \\
\hline \multicolumn{1}{|l}{ Total } & 48 & ---- \\
\hline
\end{tabular}

Considerando os depoimentos do DSC constante na IC-5, percebeu-se que o processo de adequação estrutural da Camed foi visto como extremamente complexo e transformador pelos seus gestores, especialmente quanto à nova estrutura, que demandou a criação de novas áreas e processos, como: marketing e vendas, produtos, normas e regulação, entre outros, bem como a ampliação e fortalecimento de áreas ligadas ao atendimento aos clientes, prestadores de serviço e suporte jurídico, além das questões voltadas à distribuição das atividades entre as operações da autogestão e as de medicina de grupo. Por seu turno, ao avaliar o que muda numa organização em busca da adequação ao novo ambiente, destacou-se que a mudança 
estrutural na Camed foi impactante, uma vez que a organização desenvolveu uma estrutura voltada para atender ao público da autogestão e que também atendesse às novas exigências da operação de mercado (medicina de grupo). Tudo isso confirma aquilo já discutido no referencial teórico (WOOD Jr., CURADO e CAMPOS, 1994; WOOD Jr., 2000; SANTOS, 2004) que assinala que as mudanças estruturais estão ligadas às partes de uma organização, centrando-se nas relações de poder e subordinação, na criação de novas áreas, na extinção de outras, no surgimento de novos processos, procedimentos e rotinas administrativas e de produção.

Com a inclusão da operação de medicina de grupo e a regulação tivemos que nos adaptar, criar áreas, implantar processos, criar estrutura, contratar pessoas, tecnologia, implantar tudo para atender à norma. Houve mudança estrutural bem mais forte. Passamos a ter unidades com foco no mercado. Em termos de estrutura, tivemos um novo suporte jurídico, produtos e cadastro. A abertura para o mercado promoveu mudanças com aumento da área de negócios e criação da área de vendas. A gente teve que demitir, fundir gerências, superintendências. Ao entrar no mundo da medicina de grupo, percebemos a diferença entre autogestão e medicina de grupo. Veio a questão de que era preciso se preparar, promover mudança estrutural, de pessoas, de processos e melhorar a competitividade. É outra empresa. Há processos, hoje, que jamais imaginávamos que precisaríamos ter. A Camed, antes deste processo regulatório, focava, basicamente, em área de atendimento ao cliente, na operação em si e nas áreas administrativas. Com a regulação, fez-se necessária a estruturação de uma área exclusiva para tratar destas questões, e, que pudesse acompanhar, em tempo real, os normativos e disciplinamentos da agência reguladora. Até então, não se tinha esta estrutura, ela foi criada com o advento da regulação e da medicina de grupo. Além disto, tivemos um fortalecimento de estrutura nas áreas jurídica, de produtos e na operação em si. Essas áreas tiveram que crescer.

Quadro 6 - DSC-IC-5: A inclusão da operação de medicina de grupo e a regulação promoveram mudanças estruturais na Camed.

O DSC constante no quadro 7 retrata as mudanças promovidas pela Camed em termos de tecnologia. Os gestores da Camed apontam uma série de mudanças tecnológicas conquistadas, principalmente quanto ao aprimoramento dos seus sistemas informatizados de gestão, na automação de processos e atendimento às demandas da ANS, bem como pelo desenvolvimento de programas voltados à operação de mercado, visando fazer face ao crescimento do número de clientes decorrentes do somatório da operação de autogestão com a de medicina de grupo.

\footnotetext{
Um aspecto importantíssimo foi a questão tecnológica. A Camed promoveu mudanças tecnológicas, pois tinha um sistema obsoleto e simples e passou a trabalhar com uma ferramenta mais robusta e teve que fazer várias customizações para trabalhar com autogestão e a medicina de grupo. A tecnologia mudou. Teve que adaptar nossos processos para o novo formato eletrônico demandado por todas as obrigações da ANS. Houve muito investimento em tecnologia, entrou-se com a biometria, a conectividade para tirar os carbonos dos papéis, e até para se adaptar à regulamentação e normas da ANS. Ademais, promoveram-se mudanças, implantando o acesso via internet, com informações sobre a rede credenciada, o sistema de cadastro e a comunicação com o cliente por meio do chat on-line. Contudo, a mudança não ocorreu no volume suficiente e ainda não estamos hoje $100 \%$ assistidos em tecnologia. Avançamos, mas temos muito ainda a aperfeiçoar. A Camed promoveu mudanças tecnológicas, pois, ao longo desses anos, quintuplicaram-se o número de guias e teve-se que buscar soluções tecnológicas para viabilizar isso sem quintuplicar o número de funcionários para processar estas guias. A automatização de processo foi importante para se ter ganho de escala e também a aderência à regulação. A ANS exige muitas coisas e, sem tecnologia, não teríamos a condição de atender todas as demandas.

Quadro 7 - DSC-IC-6: A Camed promoveu mudanças tecnológicas para atender às exigências da ANS e da operação de medicina de grupo.
} 
O DSC apresentado no quadro 8 relativo a IC-7 tem como ideia central a realização da profissionalização das pessoas em função das mudanças sofridas na Camed. Tais mudanças ligadas à estratégia de abertura para o mercado e também por necessidade de atender aos requisitos da regulação contribuíram para o aprimoramento profissional dos funcionários da Camed, uma vez que os mesmos se depararam com um paradigma organizacional, influenciado pelo novo mercado concorrencial e pelas demandas da regulação. Neste sentido, a Camed adotou duas abordagens. A primeira diz respeito ao processo de desenvolvimento profissional dos próprios funcionários da Camed por meio de programas de capacitação interna e de outros cursos promovidos pela ANS. A segunda levou em consideração o processo de contratação de profissionais do mercado com capacidade e competência para contribuírem com aquele novo momento de mudança que precisava ser encampado pela empresa. Assim, a preocupação em aprimorar o instrumental das pessoas para os novos desafios originados no processo de mudança, é também defendida por Fischer (1992) e Bitencourt (2004), que apontam o desenvolvimento das competências nas pessoas que compõem uma organização como fator preponderante para a modernização, execução das estratégias e, consequentemente, para a mudança.

Tivemos a nítida necessidade de nos aperfeiçoarmos para poder lidar com a operação de mercado. No âmbito das pessoas foram dois movimentos. Primeiramente, a Camed promoveu capacitação interna de alguns profissionais com potencial para assumir os novos desafios, incluindo mudanças para as novas áreas que foram formadas. Segundo, a Camed trouxe pessoas do mercado. A profissionalização dos quadros foi uma busca urgente da empresa. E isso continua até hoje. O setor da saúde suplementar é limitado no ponto de vista de formação de profissionais e, normalmente, as pessoas especializadas neste assunto estão dentro das operadoras. No caso da Camed, prioritariamente, nós formamos estas pessoas. São pessoas da casa que tiveram que buscar esta profissionalização, aqui mesmo, por meio de capacitações fornecidas pela ANS e por nós. Hoje, o funcionário da Camed é muito mais maduro profissionalmente, pois ele entende mais de concorrência, das exigências dos clientes e necessidade de negociações. Antes, era muito fechado e não se tinha a necessidade de buscar alternativas. Havia certa acomodação. Com a saída para o mercado, nós crescemos bastante profissionalmente.

Quadro 8 - DSC-IC-7: As demandas geradas em função das mudanças promovidas na Camed contribuíram para uma maior profissionalização das pessoas.

Considerando o DSC presente na IC-8, pôde-se observar que a estratégia de abertura para o mercado, com a comercialização de planos de saúde, foi apontada pelos gestores como uma significativa mudança ocorrida na Camed. Desse modo, a reprogramação estratégica que transformou uma operadora de autogestão numa operadora também de medicina de grupo impactou toda a organização e promoveu severas mudanças, no sentido de conciliar a antiga operação com as novas demandas emanadas da operação de mercado, sendo esta última fortemente impactada pelas macro mudanças advindas da regulação do setor. 
A principal mudança foi a abertura para vender planos empresariais e individuais para pessoas que não são vinculadas diretamente ao Banco do Nordeste. Esta foi a grande mudança de estratégia, isto é, adquirir mecanismos que a autogestão não proporcionava, para podermos almejar a sustentabilidade, bem como uma vitalidade maior no segmento. As mudanças macroeconômicas do sistema de saúde têm exigido, não só da Camed como de outras operadoras constantemente reavaliar suas estratégias. Foi um grande marco para a Camed no sentido de começar a fortalecer sua marca, para depois, realmente, se enraizar no mercado da saúde suplementar. A ida para o mercado foi uma busca de captação de receitas, com a motivação de levar para o este mesmo mercado o que já fazemos bem na autogestão. Além desta motivação primeira, começam a surgir outras, como maior poder de barganha com a rede credenciada por se ter uma carteira mais volumosa.

Quadro 9 - DSC-IC-8: A principal mudança estratégica da Camed foi a abertura para o mercado.

Em relação a dimensão de análise II que trata de refletir sobre o que mudou na Camed. Os DSC constantes nos quadros 6, 7, 8 e 9 mostraram-se aderentes ao referencial teórico ao constatar que a Camed mudou em relação a sua estrutura, a sua tecnologia, ao fator pessoas e a sua estratégia. Tudo isso aconteceu por conta das demandas provenientes da inclusão da medicina de grupo na sua dinâmica organizacional, bem como das exigências relativas ao processo de regulação.

\subsection{Dimensão de Análise III: Implementação da Mudança}

$\mathrm{Na}$ dimensão de análise que trata da implementação da mudança, pretendeu-se conhecer como mudou a organização. Nesse sentido, tal etapa da pesquisa centrou-se em avaliar se a mudança pretendida aconteceu com maior ênfase nas questões participativas e reeducativas ou pelo modo coercitivo/impositivo. Assim, foram encontradas três ideias centrais de acordo com a tabela 3 a seguir:

Tabela 3: Frequência por Ideia Central

Dimensão: Implementação da Mudança: Como mudou a Organização?

\begin{tabular}{|c|l|c|c|}
\hline IC & \multicolumn{1}{|c|}{ Ideia Central } & Fi & Fi\% Acum. \\
\hline IC-9 & A Camed promoveu a implementação das mudanças de forma participativa & 09 & $64,28 \%$ \\
\hline IC-10 & A Camed promoveu mudanças de cima para baixo & 03 & $86,22 \%$ \\
\hline IC-11 & A mudança, na Camed, no âmbito interno, foi colaborativa & 02 & $100 \%$ \\
\hline \multicolumn{2}{|c|}{ Total } & 14 & ----- \\
\hline
\end{tabular}

O DSC referente à IC-9 construído no quadro 10 nos remete a forma como a mudança foi implementada na Camed. Isto posto, existe nos depoimentos a percepção dos gestores da Camed de que a implementação da mudança foi realizada de forma reeducativa/participativa. Os gestores salientam, também, que a clareza quanto ao processo e a forma como a mudança foi discutida, envolvendo os funcionários por meio de grupos de trabalho e abertura para apresentação de sugestões, permitiu agregar ao processo de mudança a evolução em termos de aprendizado profissional, o que denota, em síntese, que a mudança na Camed foi implementada de forma reeducativa e dentro da lógica participativa. 
A gente conseguiu trazer ideias de todo o grupo de funcionários e muitas foram brilhantes. Com essas ideias, teve-se a condição de desenvolver mudanças urgentes, que fizeram a Camed melhorar consideravelmente. Tivemos um processo de mudança cultural, pois a equipe é grande. Não é qualquer empresa com 700 funcionários que consegue da noite para o dia mudar. A gente quis fazer da melhor forma possível e acho que se conseguiu fazer as mudanças em paz, com satisfação de todos. A mudança foi muito participativa na construção dos novos modelos sobre o ambiente que a organização iria atuar. Houve uma sensibilização, uma disseminação, uma preocupação em mostrar o novo modelo de gestão e forma de trabalhar. À época, formou-se um grupo de trabalho, que foi organizado, e algumas pessoas participaram da discussão e depois desceu para toda a organização, a princípio um menor número de pessoas, o que depois foi se ampliando. Ao longo do processo, sempre houve envolvimento do corpo funcional para administrar isto, nós aprendemos muito nesse período.

Quadro 10 - DSC-IC-9: A Camed promoveu a implementação das mudanças de forma participativa.

O DSC referente à IC-10 construído no quadro 11 mostra uma peculiaridade da implementação do processo de mudança da Camed no seu momento inicial. Nos depoimentos dos gestores da Camed constata-se que, para alguns, a implementação do processo de mudança no seu início se deu de cima para baixo. Em outras palavras, a decisão da implementação aconteceu, na alta administração, e desceu no sentido top down mesmo que, logo em seguida, os gestores tenham procurado envolver os funcionários numa perspectiva mais participativa.

Na minha visão, a Camed, inicialmente, realizou a mudança de cima para baixo. No começo, a mudança ocorreu de forma impositiva, originando-se da alta administração. Por exemplo, a determinação de entrada para o mercado originou-se da alta administração. A direção abriu o jogo falando para os funcionários se conscientizarem sobre o que estava acontecendo e o que precisava ser feito. Num segundo momento, ela trouxe os funcionários para juntos ajudarem a resolver os problemas estruturais que a Camed tinha.

Quadro 11 - DSC-IC-10: A Camed promoveu mudanças de cima para baixo.

O DSC referente à IC-11 construído no quadro 12 corrobora o DSC da IC-9. Para tais entrevistados, a implementação do processo de mudança aconteceu de forma colaborativa, tendo as duas áreas da empresa (medicina de grupo e autogestão), operando de forma cooperativa com o propósito de juntas resolverem os problemas estruturais que a Camed passou a enfrentar com sua abertura para o mercado e com o advento do marco regulatório. Isso fortalece $\mathrm{o}$ argumento de uma implementação da mudança de forma mais reeducativa/participativa do que coercitiva/impositiva.

Do ponto de vista interno, a mudança foi muito colaborativa. As pessoas compreendendo este novo momento foram chamadas a contribuir. As duas operações, autogestão e medicina de grupo colaboraram bem e as operações fluíram naturalmente.

Quadro 12 - DSC-IC-11: A mudança, na Camed, no âmbito interno, foi colaborativa.

A partir dos DSC referentes à IC-9, IC-10 e IC-11, permite-se compreender que, na dimensão implementação da mudança, a forma da mudança na Camed foi marcadamente reeducativa/participativa apesar de alguns depoimentos (quadro 11) sinalizarem que a 
mudança aconteceu, inicialmente, de forma impositiva, pois a decisão ocorreu de cima para baixo a partir de uma determinação da alta administração.

Os DSC constantes nos quadros 10 e 12 mostraram que a Camed promoveu a implementação da mudança de forma reeducativa/participativa, envolvendo as pessoas, criando grupos de trabalho, preocupando-se em disseminar a informação sobre a mudança, tendo como premissa a comunicação direta e objetiva com as pessoas. Sobre isso, Silva e Vergara (2003), bem como Santos (2004) expressam que esses fatores são fundamentais para que o processo de mudança aconteça e seja bem-sucedido, privilegiando um modelo voltado à transparência, capacitação e convencimento.

\section{CONCLUSÃO E SUGESTÕES PARA PESQUISAS FUTURAS}

Este trabalho, fruto de uma pesquisa mais abrangente sobre a saúde suplementar no Brasil, teve como finalidade analisar como as macro mudanças da saúde suplementar impactaram na dinâmica organizacional da Camed, originalmente, uma operadora de autogestão em saúde. Desta forma, o presente trabalho enfrentou o desafio de articular dois temas extremamente importantes que são por um lado, a regulação da saúde suplementar no Brasil, que, em 2013, completou 15 anos de existência; e, por outro lado, o tema mudança organizacional e suas dimensões de análise, adotando como estratégia de pesquisa, o estudo de caso simples, de uma organização que atua há 35 anos no setor.

Buscou-se estudar o impacto das macro mudanças na saúde suplementar na Camed a partir de uma abordagem da mudança organizacional que privilegia três dimensões: 1) a intencionalidade; 2) o objeto; e 3) a forma de implementação da mudança organizacional. Juntas, estas três dimensões responderam as questões ligadas a identificar o porquê, o quê e o como muda uma organização, cumprindo, por fim, o propósito desta pesquisa que foi o de identificar como as macromudanças da saúde suplementar impactaram na dinâmica organizacional da Caixa de Assistência dos Funcionários do Banco do Nordeste do Brasil S.A.(Camed).

Com base nesses elementos, conclui-se que, na dimensão intencionalidade da mudança, o processo ocorreu na Camed de forma híbrida, sendo reativa no âmbito do atendimento às exigências geradas no processo regulatório e; por outro lado, sendo voluntária, principalmente, em função da decisão estratégica de abertura para o mercado, motivada pela leitura do cenário macroeconômico existente à época. 
Na dimensão objeto, constatou-se que a Camed promoveu as mudanças estratégicas, estruturais, tecnológicas e com as pessoas, previstas no referencial teórico desta investigação.

Por fim, destaca-se que a unidade de análise empírica desta pesquisa mostrou-se plenamente aderente aos conceitos de implementação da mudança no formato participativo/reeducativo desta dimensão. Entretanto, é importante ressaltar que um achado desta pesquisa nos remete a observar que, apesar do caráter participativo e reeducativo, em sua fase inicial, o processo da mudança ocorreu de forma impositiva por ter emanado da alta administração da organização estudada, o que não altera o caráter participativo/reeducativo identificado na implementação da mudança.

Em termos práticos, esta pesquisa contribui para um melhor entendimento sobre a mudança em uma organização de saúde, porém sem ambições de generalização. Entender o processo da mudança, bem como ocorreu sua implementação, trouxe relevantes informações para a direção da Camed e configura uma memória significativa, intimamente associada à teoria que trata do tema. Em termos teóricos, ratifica-se uma abordagem acerca da mudança organizacional, a qual contribui para a reflexão e o entendimento dos motivos, do objeto e da forma como ocorre a mudança.

Como sugestões para pesquisas futuras, especialmente em relação à saúde suplementar e, tendo como ponto de análise a mudança organizacional, recomenda-se avançar em futuras investigações com outros segmentos, tais como as seguradoras especializadas em saúde, cooperativas médicas, bem assim de outros operadores do sistema, a exemplo das administradoras de benefícios. Além disso, pode-se encampar outras investigações a partir de outras abordagens metodológicas. Vale assinalar que esta pesquisa possui limitações, mormente por considerar que, sendo um estudo de caso único, a sua aplicabilidade, apresentase num âmbito intrínseco à organização estudada. Além disso, o impactado das macromudanças na dinâmica organizacional da Camed é analisado sob a ótica pura e exclusiva dos seus gestores de alta cúpula.

Acredita-se, desta forma, ter contribuído com a geração e difusão do conhecimento sobre um setor extremamente importante que é a saúde suplementar, bem como no aprofundamento de temas sempre relevantes e atuais, como os ligados aos processos da mudança organizacional. 


\section{REFERÊNCIAS}

\section{AGÊNCIA NACIONAL DE SAÚDE SUPLEMENTAR - ANS. Caderno de Informação da}

Saúde Suplementar: beneficiários, operadoras e planos. Rio de Janeiro: ANS, 2011. Disponível em: <http://www.ans.gov.br/images/stories/Materiais_para_pesquisa/Perfil_setor/Caderno_inform acao_saude_suplementar/2011_caderno_informacao.pdf >. Acesso em: 15 set. 2013.

Caderno de Informação da Saúde Suplementar: beneficiários, operadoras e planos. Rio de Janeiro: ANS, 2013a. Disponível em: <http://www.ans.gov.br/images/stories/Materiais_para_pesquisa/Perfil_setor/Caderno_inform acao_saude_suplementar/2013_mes03_caderno_informacao.pdf $>$. Acesso em: 15 set. 2013.

. Planos de Saúde e Operadoras. Rio de Janeiro: ANS, 2013b. Disponível em: <www.ans.gov.br>. Acesso em: 15 set. 2013.

ARAUJO, A. M. A regulação do mercado de saúde suplementar no Brasil: barreiras à entrada e à saída de operadoras de planos privados de assistência à saúde. Rio de Janeiro, 2004. $116 f$. Dissertação. (Mestrado em Saúde Pública). Escola Nacional de Saúde Pública, Fundação Oswaldo Cruz, 2004.

BAHIA, L. O mercado de planos e seguros de saúde no Brasil: tendências pósregulamentação. In: BARJAS NEGRI, G. G.; GONZÁLES, A. J. V. (Org.). Brasil: Radiografia da Saúde. Campinas, SP: IE-UNICAMP, Ministério da Saúde, p. 325-361, 2001.

BITENCOURT, C. C. A gestão de competências gerenciais e a contribuição da aprendizagem organizacional. Revista de Administração de Empresas, v. 144, n. 1, p. 58-69, 2004.

BRASIL. Constituição. Constituição da República Federativa do BRASIL. Capítulo da Saúde, Brasília, 1988.

BRASIL. Lei n ${ }^{\circ}$ 9.656. Regulamenta a Saúde Suplementar no Brasil. Diário Oficial da União, Brasília, 2 de junho de 1998.

CAMED. História. 2013. Disponível em: <http://www.camed.com.br>. Acesso em: 15 setembro de 2013.

CASTRO, P. M. R.; POLO, E. F.; PORTO, G. S. Treinamento, desenvolvimento e mudança: uma articulação possível e necessária. In: Anais, 32. ENANPAD, 32 2008. Rio de Janeiro: Anais... Rio de Janeiro: ANPAD, 2008.

CIEFAS. A História da Autogestão em Saúde no Brasil. São Paulo: CIEFAS, 2000.

CRESTANA, M. F. Bibliotecários da área médica: o discurso a respeito da profissão. Revista Perspectiva Científica. inf. Belo Horizonte, v. 8, p. 134-149, n. 2, 2003. 
CRUZ, M. A.; BISPO, M. de S.; CRISTÓFOLI, F.; SILVA, R. D. da. O estudo do processo de mudança na cultura organizacional de um banco estatal após a privatização: o caso Banespa. In: ENANPAD, 34, 2010. Rio de Janeiro: Anais... Rio de Janeiro: ANPAD, 2010.

FALCÃO, E. B. M.; SANTOS, A. G.; LUIZ, R. R. Conhecendo o mundo social dos estudantes: encontrando a ciência e a religião. Revista Electrónica de Enseñanza de Las Ciencias, v. 7, p. 420-438, n. 2, 2008.

FARIA, L. de O.; FISCHER, T. Privatização, mudança e evolução da estrutura organizacional em três momentos: Tebasa, Telebahia e Telemar. Organizações \& Sociedade, v. 8, n. 21, maio-ago, p. 59-75, 2001.

FISCHER, R. M. A modernidade de gestão em tempos de cólera. Revista de Administração, v. 27, n. 4, p. 58-64, 1992.

LEFEVRE, F.; LEFEVRE, A. M. C. Depoimentos e Discursos: uma proposta de análise em pesquisa social. Brasília: Liber Livro Editora. 2005.

MACHADO-DA-SILVA, C. L.; FERNANDES, B. H. R. Mudança ambiental e reorientação estratégica: estudo de caso em instituição bancária. Revista de Administração de Empresas, v. 38, n. 4 , p. 46-56, 1998.

MACHADO-DA-SILVA, C. L.; GRAEFF, J. F. Desenvolvimento e institucionalização de práticas em espaços sócio-territoriais: a região dos Campos Gerais. Organizações \& Sociedade, v. 15, n. 45, abr-jun, p. 233-252, 2008.

MONTONE, J. O Impacto da Regulamentação no Setor de Saúde Suplementar. Ministério da Saúde, Agência Nacional de Saúde Suplementar. Rio de Janeiro: ANS, 2001. Disponível em: <http://www.ans.gov.br/images/stories/Materiais_para_pesquisa/Materiais_por_assunto/Prod EditorialANS_Serie_ans_vol_1.pdf>.Acesso em: 15 set. 2013.

OCKÉ-REIS, C. O.; ANDREAZZI, M. de F. S.; SILVEIRA, F. G. O mercado de planos de saúde no Brasil: uma criação do Estado? Revista de Economia Contemporânea. Rio de janeiro, v.10, n.1, abr. 2006.

OLIVA, E. de C. A privatização de empresas siderúrgicas brasileiras: reflexos na gestão de recursos humanos. Revista de Administração Contemporânea, v. 6, n. 1, jan-abr., p. 145$161,2002$.

PEREIRA, M. F. Mudanças estratégicas em organizações hospitalares: uma abordagem contextual e processual. Revista de Administração de Empresas, v. 40, n. 3, p. 83-96, 2000.

PEREIRA, V. S. Houve mudanças no perfil das operadoras de planos de saúde após a criação da ANS? Um estudo exploratório. Rio de Janeiro: ANS, 2010. Disponível em: < http://www.ans.gov.br/images/stories/Materiais_para_pesquisa/Materiais_por_assunto/ProdE ditorialANS_Textos_para_discussao_01.pdf >. Acesso: 15 set. 2013. 
PINTO, M. C. S.; COUTO-DE-SOUZA, C. L. Mudança organizacional em uma empresa familiar brasileira. Revista de Administração Pública, v. 43, n. 3, p. 609-634, 2009.

PÓ, M. Institucionalidade e desafios da regulação na área de saúde no Brasil. In: SANTOS, N. (Org.). Gestão pública e relação público privado na saúde. Rio de Janeiro: Cebes, p. 243-266, 2010.

PROTIL, R. M. Mudança organizacional frente a novas tecnologias: um estudo de caso em uma cooperativa agroindustrial. In: ENANPAD, 27, 2003. Atibaia: Anais... Atibaia: ANPAD, 2003.

RIBEIRO, J. M. Regulação e contratualização no setor saúde. In: BARJAS NEGRI, G. G.; GONZÁLES, A. J. V. (Org.). Brasil: Radiografia da Saúde. Campinas, SP: UNICAMP, p. 410-443, 2001.

SANTOS, F. P. A regulação pública da saúde no Brasil: O caso da Saúde Suplementar. Campinas, 2006. 226f. Tese (Doutorado em Saúde Coletiva). Universidade Estadual de Campinas, 2006.

SANTOS, M. J. B. Qual é a lógica que orienta a administração dos planos de autogestão em saúde? Porto Alegre, RS: [s.n.], 2006. Disponível em: <https://www.lume.ufrgs.br/bitstream/handle/10183/12331/000560003.pdf?sequence=1>.

Acesso em: 15. Set. 2013.

SANTOS, M. V. Redes sociais informais e compartilhamento de significados sobre mudança organizacional: estudo numa empresa petroquímica da Bahia. Salvador, 2004. 173f. Dissertação. (Mestrado em Psicologia). Universidade Federal da Bahia, 2004.

SILVA, J. R. G.; VERGARA, S. C. Sentimentos, subjetividade e supostas resistências a mudança organizacional. Revista de Administração de Empresas, v. 43, n. 3, p. 10-21, 2003.

SOUZA-SILVA, J. C. Aprendizagem organizacional: desafios e perspectivas ao desenvolvimento de comunidades de prática. Salvador: Conhecimento Superior, 2007.

UNIDAS. Pesquisa nacional 2001/2002. União Nacional das Instituições de Autogestão em Saúde. São Paulo, 2003. Disponível em: <http://www.unidas.org.br/periodicos/arq_periodicos/pesquisa_2001_2002.pdf>. Acesso em: 15 set. 2013.

WOOD JR., T. Mudança Organizacional: introdução ao tema. In: WOOD JR., T. (Org.). Mudança Organizacional: aprofundando temas atuais em administração de empresas. 2. ed. São Paulo: Atlas, 2000.

WOOD JR., T.; CURADO, I. B.; CAMPOS, H. M. Vencendo a crise: mudança organizacional na Rhodia Farma. Revista de Administração de Empresas, v. 34, n. 5, p. 62 79, 1994.

YIN, R. K. Estudo de Caso. Planejamento e Métodos. 2. ed. Porto Alegre: Bookman, 2001. 